\title{
NEW BORN CARE PRACTICE OF THARU MOTHERS
}

\author{
Om Prasad Baral \\ Department of Health Education, T.U., TRM Campus, Birgunj \\ Email: ompbaral@gmail.com
}

\begin{abstract}
At birth every newborn must adopt quickly to life outside the womb. Most newborn breathe and cry at birth with no help. The care need to give immediately after birth is simple but important. Immediate subsequent care of newborn are; sleep, loving care, protection from infection, bathing, cord care, immunization, breast feeding, vitamin A, safety and security. This paper explores the newborn care practice of the Tharu mothers who have less than one year child in Kolbi $V D C$ of Bara district. The findings of the of the research has indicated that the majority of the respondents were regular antenatal checked up, conscious of cord cutting practice, satisfied immunization, colostrums feedings and oil bath.
\end{abstract}

\section{Keywords}

New born care, ANC, cord cutting practice, colostrums feeding practice, immunization.

\section{Introduction}

New born care is very important for holistic development and healthy life of a baby which simply requires highly expensive technological equipments. The new born mortality can be significantly reduced through improved household practices and use of basic community health services. Several efforts have been made to reduce the child mortality in Nepal. The government has also formulated the national neonatal health strategies with the goal to improve health and survival of the newly born babies focused on increasing the adaptation strengthening neonatal health service.

Individual from birth to under four week of age $(>28)$ is called new born or neonate. Infant further first week of life ( $<7$ days or $<168$ hours) is known as early neonatal period. Late neonatal extended from $7^{\text {th }}$ to 28 days ( Ghai,2005). 
In Nepal infant and neonatal mortality is very high, IMR 48/10oo lives birth, NMR 34/100o live birth PMR 47.4/10oo live birth and still birth. It is estimated that in Nepal nearly 50,0oo children under one year of age die every twelve months. Two third of them die within 28 days of age, resulting in over 30,000 deaths per year. Among those dying with neonatal period 20,00o(two third) die in first week of life. Nearly the same numbers of babies are still birth. More than 16,00o of those dying within the first week of life die within 24 hours. This means that three to four newborns are dying every hour in Nepal (chitrakar, 2010).

According to hospital based data, the major direct cause of neonatal death in Nepal are: infection, birth asphyxia, prematurity and hypothermia. Similarly poor pregnancy health, inadequate care during pregnancy, lack of delivery care, low birth weight, and inadequate new born and post partum care are underlying causes. The state of new born in Nepal still compares poorly to that of almost all other developing countries. Nepal neonatal mortality rate is the third highest in the world (save the children Fund, 2002). There is a death of information on the state of new born in Nepal, with the exception of some hospital based studies that have attempted to highlight the situation. Women who did not deliver their last born child in a health institution were asked about the practice of taking care of new born, ;including the use of safely delivery kits, cord cutting practices drying and bathing practices and health services for new born children. The primary care of newborn includes the proper practice of cutting the umbilical cord.

Traditionally, the cord is usually cut with a razor, blade, knife, sickle, or even a piece of wood, none of which is generally sterile. In some cultures the cord is not cut until the placenta is delivered and it is cut only after cord pulsation stops upon the delivery of the placenta (SCF, 2002)
Every year globally an estimated four million babies die before they reach the age of one month. Main causes of newborn death around the world are infection (42\%), birth asphyxia and birth injuries (36\%), Congenital birth defects $(11 \%)$ and prematurity and preterm birth $(11 \%)$ causes of neonatal mortality are the risk of dying is the greatest during the first twenty four to forty eight hours after birth (Park, 2010). In south Asia region also $30 \%$ of neonatal death occurs due to preterm birth 27 percent sepsis, 23 percent pneumonia and birth asphyxia 6 percent congenital abnormality 4 percent tetanus 3 percent diarrhea and 7 percent other causes.

New born care is very important for the proper development and healthy life of baby. It is crucial period in the lives. New born under-goes many profound changes at the movement of birth like respiratory change, thermal change and circulatory change. The most profound physiological change required of the new born is transition from fetal or placenta circulation to independent respiration (Wong, 2003). How well these neonatal adjust these major adjustment depend upon his or her genetic endowment, the competency of these recent intrauterine environments the care received during immediate neonatal period (WHO, 2004). These initial adaptations are crucial to their subsequent well being and also should be facilitate by the wife at the time of birth. All babies need basic care to help ensure their survival and well being which is known as essential new born care. Basic care of new born means intervention for all infant to meet their physiological needs: prevention of infections due to unseemliness at birth and later, appropriate nutrition by early exclusive and frequent breast feeding; initiation of breathing by resuscitation when needed and give good start for preterm and small newborns (WHO, 2006).

WHO (2007) reported that Nepal government has standardized the content for maternal and new born health communication which 
focus the following practices essential new born care practices; dried new born with clean cloth, wrap from head to toe, initial breastfeeding (colostrums) within one hour of birth, cut the cord with a clean blade and tie it clean material, nothing applied to the cord avoid bathing of new born for the first 24 hours, BCG immunization.

\section{Methods}

The survey method was adopted in this study. The main informants for the study were married Tharu women with one year child. Out of 1030 total house holds in the selected area, 103 houses were selected by adopting random sampling method. The structured interview schedule developed by the author himself was used as the main tool for collecting primary data. After collecting the necessary information, they were analyzed quantitatively.

\section{Results and discussion}

The results have been presented on the following heads:

Antenatal check: Antenatal check up is very important for the health of mother and fetus. Most of the Tharu mothers had good practice of ANC while some of them had not checked up during pregnancy. It should be increased by ANC awareness program in Tharu community. Figure 1 shows the majority of the mothers $(81 \%)$ had antenatal checked up and least of mothers (19\%) had not checked during pregnancy.

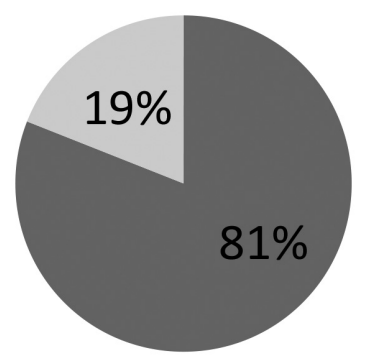

Figure 1: Tharu mothers' practice on ANC check up.
Immediate new born care: Figure 2 represents that majority of the mothers $(76 \%)$ answered that immediate new born care keeps the baby warm, 19 percent answered to keep close to mother, three percent answered to cut the cord and remaining two percent of the mothers answered to give the baby bath. It may be said that they have positive practice on immediate new born care due to effective role done by FCHV (Female Community Health Volunteer).

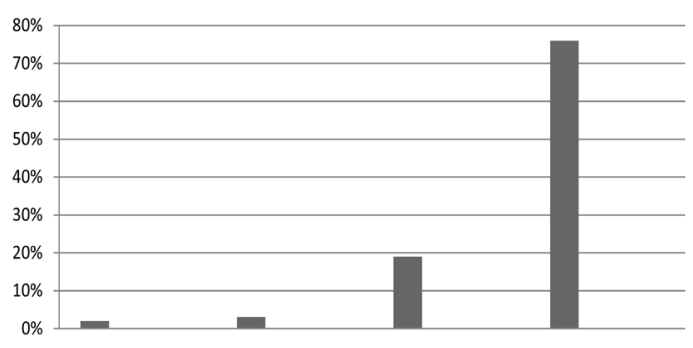

Fig 2: Tharu mothers' immediate new born care.

Cord cutting practice of new born baby: Cord cutting practice is important to cut cord after the birth of a baby. But it should be done carefully otherwise there will be risk of different kinds of infectious disease on it. Neonatal tetanus has been associated with the use of unsterilized cord cutting instrument. Figure 3 reveals that 89 percent of the mothers used to cut the cord with new razor. Eight percent used scissor and 3 percent used other instrument cutting the cord. It indicates that they are conscious for cord cutting practice which is not safe in Tharu mothers and slowly changing their concept from traditional to modern ways.

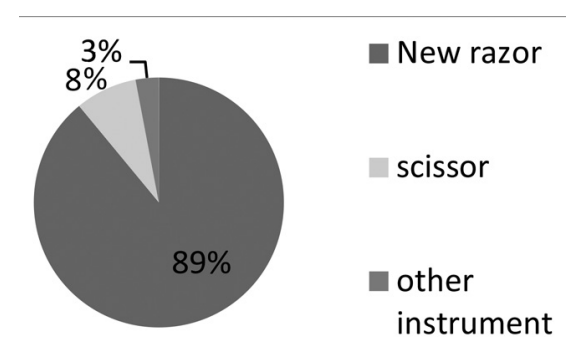

Fig 3: Tharu mothers cord cutting practice 
Colostrums Feeding Practice: Figure 4 indicates that 90 percent Tharu mother feed the colostrums to their neonate and rest of them is against this practice. First milk is known as "colostrums" prepared on mother's breast immediately after delivery. Colostrums provide the natural immune power. It is "natural vaccine". It carries immunity to disease and high nutritive value to the neonate. It was also found that most of the Tharu mothers feed colostrums to their neonates unknowingly and some due to the force of their parents who are educated better know the advantages of colostrums for the newly born babies.

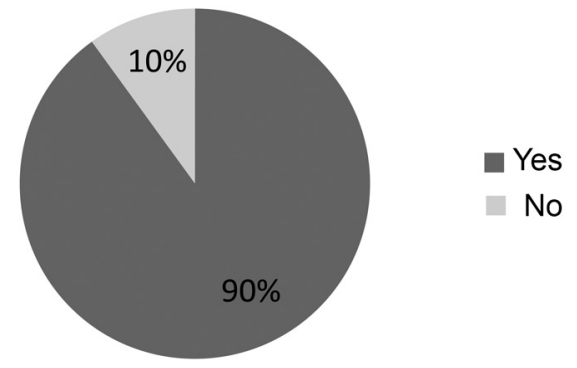

Fig 4: Colostrums feeding practice

Weaning practices: There is no doubt; the first food is the breast feed for new born, however only the breast feed can't work when the baby grows and develops. Therefore, some supplementary food is necessary after 5/6 months. Such system is called weaning practice. Weaning practices refers to the process of gradually reducing feeding a baby with its mother milk and starting feeding with solid food.

Table 1: Weaning practices

\begin{tabular}{|l|l|l|}
\hline S.N. & Weaning food & Percentage \\
\hline 1 & Porridge & 5 \\
\hline 2 & Super flower & 30 \\
\hline 3 & Rice/cereal & 60 \\
\hline 4 & Bottle milk/ Horlicks & 5 \\
\hline
\end{tabular}

Table 1 shows that 60 percent used rice and cereal, 30 percent used super flower, 5/5 percent used porridge and bottle milk / horlicks as supplementary for babies. The practice of feed rice and cereal is better here because of very significant role played by the media of communication in this regard.

Immunization Practice: Immunization is the means of protection against the results of infectious diseases within the human body. WHO recommended that children receive the complete schedule of vaccination before twelve months of age. Immunization practice was satisfactory due to the accessibility of health service and they had positive attitude towards vaccination.

Table 2: Immunization Practice

\begin{tabular}{|l|l|l|}
\hline S.N. & Immunized & Percentage \\
\hline 1 & Yes & 91 \\
\hline 2 & No & 9 \\
\hline
\end{tabular}

Table 2 indicates that $91 \%$ of mothers babies received immunization and only $9 \%$ of mothers' babies didn't receive immunization

Practice of oil bathing: Table 3 reveals that $100 \%$ of respondents' oil bath their babies in sun. In this community though some of the respondents are illiterate they follow traditional trends and the literate respondents are also following this practice due to the advantages of oil bathing. Hence this practice was found satisfactory due to cultural transformation.

Table 3: Practice of oil Bathing

\begin{tabular}{|l|l|l|}
\hline S.N. & Practice of oil bathing & Percentage \\
\hline 1 & Yes/ Sunbath & 100 \\
\hline 2 & No & o \\
\hline
\end{tabular}

\section{Conclusion}

Neonatal care is an important component of national reproductive health strategy in Nepal. The national reproductive health program, which aims to reduce neonatal mortality, has always intended that neonatal health component can be developed as a 
separate document. In conclusion, it has been found that majority of the respondents were ANC checked up, immediate newborn care, satisfactory cord cutting practice, colostrums feeding practice, weaning practice, immunization and oil bathing practice.

\section{References}

Chitrakar, Ganga (2010). Family Health and Reproductive Health. Kathmandu: Makalu

Ghai, O.P (2004). Essential paediatric (6 ${ }^{\text {th }}$ ed). New Delhi: CBC

Park, K. (2010). A text book of preventive and social medicine. India: Banarashiside Bhanot Publication house.
Save the children Fund (2002). Formative Research on New Born Care in the communities of Kailali. Kathmandu: SCF,US/Nepal.

WHO (2004). New Born Health policy and Planning Frame work part I. Overview for Policy: Aauthor.

WHO(2006). Saving Newborns Lives Initiative. New Delhi: WHO Regional Office for South East Asia.

Wong (2003).Nursing care of infant and children ( $7^{\text {th }}$ ed). London: Mosby Company. 